\title{
Tale of two institutions: Exploring collaboration in research partnerships
}

\author{
NICKY SOLOMON \\ University of Technology, Sydney, Australia (Nicky.Solomon@uts.edu.au) \\ DAVID BOUD \\ University of Tecbnology, Sydney, Australia \\ MARIA LEONTIOS \\ NSW Department of Education, Australia \\ MARET STARON \\ Professional Development Network, NSW Department of Education, Australia
}

\section{Introduction}

A drive to collaborate has become a pervasive feature of contemporary research. Collaboration is now a term that has come to have very positive connotations. Researchers should engage with external partners, the contexts they are working in and with the concerns and issues of others. Without an emphasis on collaboration we are not seen as relevant, understanding of priorities or committed to our institutions. What is the reality of such collaborations, what is involved in them and how are they made to work? This article explores a particular research partnership in which the authors are currently involved. By so doing we hope to identify some of the key features of successful collaboration from the perspective of researchers themselves.

The partnership involves two Australian educational institutions, the University of Technology, Sydney (UTS) and the Department of Education and Training (DET). DET is a very large state government department responsible for the state school and vocational education system of New South Wales. Together UTS and DET have obtained an Australian Research Council grant as part of the Strategic Partnerships with Industry Research and Training (SPIRT) programme. The research aims to determine the extent and nature of the significance of informal learning and its contribution to organisational performance.

In tune with the collaboration process, we, the chief investigators (from UTS) and the industry researchers (from DET), are co-authoring this article. Also in the spirit of the 'work as learning' focus of the research, we are collectively using the research process as an opportunity to explore the way we, as researchers, are workplace learners. This exploration, as exemplified in this article, involves a reflexive commentary on our own collaborative research practices. This commentary involves the development of a case study on 'real' people doing collaborative research in a particular sociocultural context. However, we will also use this reflexive commentary of a 'real life collaboration' to consider methodological processes and conditions that can further develop current understandings of collaborative research practices. 
The article begins by discussing the contemporary context of collaborative research and of our enquiry and then briefly considers the significance of this form of research in relation to existing collaborative research models. We then describe the various reflexive practices that we used to deliberately explore the complexities of collaborative research. The first is an explication of the different layers of collaboration in this research process. The second is an analysis of some texts that have been produced during one of the layers of collaboration - the UTS researchers and the DET investigators in the planning stage of the research project. The texts are tapescripts of audio-recordings of our planning sessions as well as individual narratives of our experiences that each of us has written.

The project and our commentary are located in Australia. However, arguably, many of the experiences are global ones, as most universities and educational institutions in postindustrial countries experience and respond to globalising processes in similar ways.

\section{Contemporary context of collaborative research}

Collaborative research is not a new phenomenon (Godin, 1998). However, we recognise that the current discourses within which collaborative research is located signify a substantial shift in its meanings and practices. While, certainly in earlier decades, the academy had a relationship with the 'real' world, this relationship was one of its own choosing and more or less on its own terms. As indicated by many other writers (eg, Gibbons et al, 1994; Stronach and Maclure, 1997; Usher, 2000), the political, social and economic conditions in which universities now do research is very different. We will briefly draw attention to some of the manifestations of these conditions that we believe have contributed to not only the current 'celebration' of collaborative research but also its practices.

- Researchers and educators now work in a knowledge sector or industry which is often described as part of a knowledge economy. In this economy, knowledge is produced and marketed in a many different locations with a growing number of participants. Universities therefore have become only one of a number of 'knowledge' producing organisations.

- As researchers and educators, we experience not only the devaluing of disciplinary knowledge and a permeability of disciplinary boundaries but also the breakdown of institutional boundaries.

- 'Real' world imperatives drive knowledge production. The rewarding of research that focuses on problem-solving projects is symptomatic of the increased demand for applied knowledge.

- Government views about the relationship between research and economic activity are driving changes in research funding arrangements. These changes are manifested in:

- an increase in collaborative research partnerships where industry contributes to the research costs; and

- increasing pressure on universities to view their work in commercial terms.

- Increasingly academics, like other employees, align their individual learning goals with those of the organisation and increasingly academic work is managerial.

- Increasingly academic performance is scrutinised by and accountable to bodies external to the academic community. 
These features are not simply a neutral backdrop to collaborative research. Rather they are features that contribute to the various struggles and tensions that emerge throughout the collaboration processes.

\section{Collaborative research models}

Given the new context and the new roles of the partners in government, industry and university partnerships, we suggest that we need not only to recontextualise our research practices but also to reconceptualise them. While collaborative research does not in itself imply a particular research model, there are a number of existing research practices that are frequently drawn upon, particularly in the field of education. These practices include participatory research, action research, collaborative inquiry and experiential research.

Our initial efforts to reconceptualise collaborative research take account of these various practices. We draw on a number of theoretical understandings that position 'collaboration' in a particular way. One of these is the work on new modes of knowledge production where writers such as Gibbons et al (1994) draw attention to changes in researcher performances and accountabilities as institutional conditions drive crossinstitutional partnerships. In this work we observe how academics now struggle with the various stakes involved in doing 'relevant' and 'useful' research in the site of application.

For our purposes, another relevant theoretical framing is the humanistic approach as exemplified in the writing of Rowan (1981). In this work, he argues against the 'alienation' of research subjects that is inevitable when subjects are treated only as fragments, particularly when only certain kinds of behaviours of the subjects are counted. In his model of collaboration he rejects any idealisation of collaboration. This rejection acknowledges that, in most practical situations, collaboration has to take into account that all parties will have different, and at times contested, stakes in the process and the outcomes.

A third theoretical understanding that is influencing our speculations is that adopted by post-structural researchers. This approach challenges the separability of the researcher and the researched and any notion of an independence of knowledge produced from its sociocultural site and practices (Kuhn, 1970; Usher, 1997). In poststructural terms, knowledge is contingent, contextual and linked to power. Also relevant to our conceptual interests is the understanding of the centrality of language, discourses and texts in the construction of knowledge (Lee and Poynton, 2000).

Drawing on these approaches a reconceptualisation might be one that challenges conventional ideas about when the collaboration begins and ends (eg, in SPIRT grants, evidence of collaboration that precedes the research is a requirement in the application process). Importantly also, this reconceptualisation needs to draw attention to the different layers of collaboration. That is, it needs to engage with the multiple relationships, the different stakes and the multiple points of contact, including during the negotiation of the partnership, the writing of the application, the planning stage as well as during the project itself and in the dissemination of the outcomes. And also with the various communication and planning strategies that work best given the various (and at times contradictory) interests of the partners. 


\section{Different layers and relationships}

As indicated in the introduction, our exploration of collaboration in our project began with an identification of these various layers. In the project, in the broadest sense, the key collaborative relationships are between:

- UTS and DET investigators (the co-authors);

- UTS and DET investigators and Institute Management (the Institutes run networks of technical and further education colleges in a particular geographical area); and

- UTS and DET investigators and staff at worksites (within the Institutes/colleges).

In our consideration of what collaboration means at each level, taking account of the writing of Rowan (1981), we have to be realistic about what each wants from the process and these 'wants' need to be identified at an early stage. With this understanding we have tentatively identified the various stakes of each of the collaborators, ${ }^{1}$ as follows:

- UTS researchers (from the Faculty of Education): want to engage in research that leads to insights into workplace learning and how it is fostered in a way that can withstand critical peer scrutiny in the international academic community as well as in professional communities. They want to maintain and enhance a productive working relationship with DET and collaboration with the Institutes for this project and to enhance the standing of UTS for future research and collaboration.

- DET investigators (from the Professional Development Network): want to be involved in research that links directly to their core business of learning and professional development. They would like the outcomes of the research to better position them in looking at work-based learning strategies. They want outcomes that can be used for professional development purposes in DET. They want to form closer relationships with the Institutes and to be responsive to the needs of their Institute clients.

- Institute Management: are likely to want to be involved in cutting-edge innovations that will enhance their standing with the community they serve, the department and the vocational education and training sector generally. They want practical outcomes that will improve learning for their staff in cost-efficient ways.

- Staff in worksites: there is likely to be a high variation in their motivation for their involvement in the research. We anticipate a mixture of personal ambition, commitment to their work and awareness of their positioning within their organisation. Variation will, in part, be dependent on the cohesiveness of the workgroup and the extent of their interests.

- All parties: will have an interest in how their participation in the project is represented to the various audiences. These include the Government and academic and professional communities. There may be some resistance if the research is understood to be one of surveillance involving excessive scrutiny.

\section{Exploring UTS researchers' and DET investigators' partnership}

As our research is in its early stages, our commentary is confined to the initial planning stage, where the UTS researchers and the DET investigators plan the data collection 
phase, which includes establishing relationship with the 'research sites', the managers and the work teams. Our reflexive commentary involved the production of two sets of texts - language in action texts, which are tape recordings of our planning meetings, and more abstract texts, which are reflections on the action. These are personal narratives on our experiences of this initial collaborative process. Our analysis began with an assumption of the importance of the project planning process as one of the gluing processes that help to bring together UTS researchers and DET investigators. Together we negotiated the framing of the analysis around the areas that we considered to be critical ones. These provided a guide for the writing of each of our stories and included:

- how solidarity is constructed, that is, how the four individuals representing two institutions build a partnership;

- understandings about the different strengths of each of the partners and their complementarity regarding the partnership and how these are spoken about;

- power relationships between the collaborators and whether or not there was any evidence of hierarchy within the partnership;

- how differences are negotiated; and

- how the nature of project itself (uncovering workplace learning) influences the way researchers position themselves in the research and negotiate the planning.

An important, while not unexpected, finding in the analysis of the tapescripts was the enormous amount of interpersonal work that happens in the setting up stage of the project. This construction of the foundation of such a partnership is evident in the language choices that both signal and construct an involvement in shared worlds. This includes:

- the use of humour;

- the use of chat about personal details of lives outside the project;

- the constant use of 'we', foregrounding group identity rather than individualised identities;

- the reference to our past history to suggest group cohesion (ie, raising the topic of previous joint work);

- the use of clauses that demonstrate our appreciation of others' suggestions (eg, 'That's a really good point.' 'That would be fabulous.'); and

- the use of interpersonal adjuncts (eg, 'I think', 'kind of', 'I am just', 'you know') which indicates that a proposition is open to negotiation.

The effectiveness of these language practices (and the accompanying 'comfort' with each other) is also evident in the way the researchers take risks in raising some of the various contradictions and dilemmas of the project. For example, at one meeting we remind ourselves of the risks in uncovering informal learning. We talk about the 'dark side of uncovering [learning] in terms of turning it into another managed learning process...destroying the phenomenon that we are trying to uncover...intervention change(s) its characteristics'. We also speak of issues related to our concern with our own engagement with managerial discourses in the research proposal, particularly in relation to linking productivity gains to uncovering learning.

The tapescripts reveal interesting issues around power relations. This is evident not 
so much through an analysis of the clauses or phrases but rather through a consideration of the location of the meetings (at UTS) and the particular roles of the researchers in the meetings. The authority of the academics could, to a certain degree, be embodied in these structural arrangements. For example the chief investigator (an academic) is the chair of the planning meetings, and while the agenda is discussed and open to change, the chair has formulated it and also initiates and closes each of the items.

The negotiation of differences is revealed in several places. An important example is a discussion on the wording of a post-graduate research scholarship advertisement to be placed in the media. The industry partner picks up and challenges the name of the project. The discussion unfolds into one that explores a key issue within the research whether or not it is about learning in the public sector, about learning in an educational institution and the significance of these context specificities.

In the analysis of the stories, rather than examine the grammatical realisations in the texts, we considered the similar and different ways the writers positioned themselves around the areas that we had identified as important in collaborative work - 'shared expectations of this project' and 'partnership building'. Each researcher expresses strongly the way their involvement in the project has individual and organisational gains. In individual terms, for each researcher the focus of the project links in with their individual 'academic' interests (both workplace learning and working collaboratively with those outside their own work environment). In organisational terms, all researchers point to a number of values. There are institutional rewards for winning a government-funded project and there are professional rewards for the anticipated new knowledge ('cutting edge') to be produced through this 'complementary' partnership (ie, 'the development of new ways and approaches of looking at things'). There is also a shared expectation that this project is likely to lead to further collaborations.

All collaborators expressed very strong views on the factors that contribute to the building of an effective partnership. A critical factor is considered to be 'getting on' with people. This is confirmed in the analysis of the tapescripts of the meetings that foregrounded the role of interpersonal relationships. In the stories 'getting on' is connected to the number of common characteristics of each of the institutions and the partners. This includes the fact that both institutions are in the same industry, both are large corporatising bureaucracies and the fact that there is a 'multi-layered history between adult education at UTS and the TAFE part of DET' - institutionally and between individuals on this project. Reference is also made in the stories to 'a common commitment to learning and professional development' where the two organisations bring together academics and practitioners, pooling their talents and resources to embark upon an investigation that would not be possible as individual organisations. Connected to the overlapping interests is a previously unstated shared goal of each of the researchers, that is, each has a desire to explore the research process and each understands themselves as a workplace learner.

Interestingly there are different views on the power relations of the DET and UTS research team and on whether there is a hierarchy within the partnership. While the DET partners feel it is not an issue, the UTS partners do suggest that there is an implicit hierarchy in the way the academics are seen as the 'research experts', while the industry partners have institutional knowledge as well as a vital access and support role. Several comments are made that acknowledge that the relationship between the UTS and DET researchers is only one of the many relationships that will be encountered. There is an anticipation that the remaining layers may present more 
complexity and conflict. Nevertheless it is also thought that this initial building of a 'friendly and cooperative relationship' will enable the 'team' to confront some of the 'tricky' issues.

It is also worth noting that the writing of this article became an additional text that exposed some of the complexities around collaboration. It became a site that drew attention to the ongoing negotiation of differences that are intrinsic to collaborative efforts. The key issue in this case was the different ways in which we, the writers, as a single unit, were representing ourselves in 'public', in this instance to an academic audience. The UTS investigators wish to represent themselves as 'academics'. The writing of the article is therefore understood as an academic performance where academics represent themselves and their experiences in a critical and conceptual way. However, for the DET investigators, the article was understood as a different kind of performance - one that involves a more descriptive airing of work in progress.

\section{Experiencing collaboration}

What can we draw from our experience of this collaboration? It is apparent even at this stage of our partnership that any conceptualisation of collaboration in research partnership should include consideration of the following:

1. The collaborative cycle builds on connections between the partners before the project.

2. Collaboration is a messy business and we as researchers, should not be trapped by an idealisation of it.

3. There are many layers of collaboration and there are many relationships within each. While each involves various practices, at the same time they are not discrete.

4. Building collaborative relationships is an ongoing process. The building of this relationship does not end with the success of the application nor at the end of the planning stage.

5. Building in reflexive processes (both individual and group) can benefit the collaborative process. These processes work well when the partners are involved in common reflexive tasks - with deadlines, such as conference papers.

6. Collaboration works best when everyone has a stake in it and this stake has both personal and organisational dimensions.

Collaboration is a dynamic process that has to be reinvented at each stage of development. It involves attending to personal relationships, the dynamics of working groups and the stakes of the various partners. It is also highly relational: particular strategies that work in one context will not be applicable in another. It does have its particular satisfactions though and can lead to outcomes to which all parties can subscribe.

\section{Note}

1. The descriptions of the stakes of the UTS Researchers and the DET Investigators draw on the personal narratives written by each, while the descriptions of the Institute Management and Staff at worksites are speculative. 


\section{References}

Gibbons, M, Limoges, C, Nowotny, H, Schwartzman, S, Scott, P and Trow, M (1994). The New Production of Knowledge: The Dynamics of Science and Research in Contemporary Societies, London: Sage.

Godin, B (1998). 'Writing performative history: the new new Atlantis?', Social Studies of Science, vol 28, no 3, pp 465-83.

Kuhn, T S (1970). The Structure of Scientific Revolutions, Chicago: University of Chicago Press.

Lee, A and Poynton, C (2000). Culture and Text, St Leonards, New South Wales: Allen and Unwin.

Rowan, J (1981). 'A dialectical paradigm for research', in Reason, P and Ranson, J (eds), Human Inquiry: A Sourcebook of New Paradigm Research, Chichester, UK: John Wiley \& Sons.

Stronach, I and Maclure, M (1997). Educational Researcb Undone: The Postmodern Embrace, Buckingham: Open University Press.

Usher, $\mathbf{R}$ (1997). 'Telling a story about research and research as story-telling: postmodern approaches to social research', in McKenzie, G, Powell, $\mathrm{J}$ and Usher, R (eds), Understanding Social Researcb: Perspectives on Metbodology and Practices, London, Falmer Press.

Usher, R (2000). 'All change? The university in the 'real world', Keynote paper at the Working Knowledge Conference, 10-13 December 2000, University of Technology, Sydney, Australia 


\section{Studies in the Education}

Volume 33 Number 2 October 2001

\section{Contents}

89 EDITORIAL: CHANGING KNOWLEDGE? KNOWLEDGE PRODUCTION IN THE EDUCATION OF ADULTS

Richard Edwards

95 TRAVELLERS' TALES: FROM ADULT EDUCATION TO LIFEIONG LEARNING.. AND BEYOND

Christine Jarvis

100 BITS OF BAGGAGE AND WANDERERS TALES: TOWARDS THE CONSTRUCTION OF A NEW THEORETICAL FRAMEWORK FOR COMPARATIVE ADULT EDUCATION Lore Arthur

109 IMMIGRANT WORKERS' JOURNEYS THROUGH A NEW CULTURE: EXPLORING THE TRANSFORMATIVE LEARNING POSSIBILITIES OF PHOTOGRAPHY Melina L. Gallo

118 HEAR OUR STORIES: RELATIONSHIPS AND TRANSFORMATIONS OF WOMEN EDUCATORS WHO WORK OVERSEAS Carol R, Lyon

127 KNOWLEDGE AND THE ENTERPRISING SELF: WORKPLACE REFUGEES NAVIGATING ENTREPRENEURIAI DISCOURSE Tara Fenwick

135 TALE OF TWO INSTITUTIONS: EXPLORING COLLABORATION IN RESEARCH PARTNERSHIPS

Nicky Solomon, David Boud, Maria Leonitios and Maret Staron
143 TOURING A TEXT: THE HANDBOOK OF ADULT AND CONTINUING EDUCATION Janice Malcolm

147 UNRAVELLING THE STORY OF A MILESTONE TEXT: TALES FROM THE HANDBOOK OF ADULT AND CONTINUING EDUCATION Nod Miller, Paul Armstrong, Ronald M. Cervero, Richard Edwards, David Gosling, Elizabeth R. Hayes, Juanita Johnson-Bailey, Linden West, Arthur L. Wilson and Miriam Zukas

163 PUBLISHING QUALITATIVE ADULT EDUCATION RESEARCH: A PEER REVIEW PERSPECTIVE

Edward W. Taylor, Julie Beck and Elaine Ainsworth

180 PATTERNS OF EMPOWERMENT IN INDIVIDUALS THROUGH THE COURSE OF A LIFE-SKILLS PROGRAMME IN SOUTH AFRICA

Ruth M. Albertyn, Cbris A. Kapp and Cornie J. Groenewald

201 CHALLENGING THE DISCOURSE OF INCLUSION AND EXCLUSION WITH OFF LIMITS CURRICULA Julia Preece

217 STALLING THE LEARNING PROCESS GROUP DYNAMICS IN CYBERSPACE Mike Davis and Sue Ralph

230 BOOK REVIEWS

247 INDEX TO VOLUME 33 


\section{Studies in the Education of Adults}

Studies in the Education of Adults is an international refereed journal, appearing biannually in April and October. It is addressed to academic specialists, postgraduate students, practitioners and educational managers who wish to keep abreast of scholarship, theorybuilding and empirical research in the broad field of education and training for adults.

\section{Editorial Board}

$\begin{array}{lll}\text { Roseanne Benn } & \text { University of Exeter } & \\ \text { Stephen Brookfield } & \text { University of St. Thomas, Minnesota } & \\ \text { Janet Bunker } & \text { Anglia Polytechnic University } & \text { Reviews Editor } \\ \text { Kathryn Ecclestone } & \text { University of Newcastle upon Tyne } & \\ \text { Richard Edwards } & \text { University of Stirling } & \text { Editor } \\ \text { John Field } & \text { University of Warwick } & \\ \text { Chris Jude } & \text { London Borough of Islington } & \\ \text { Mal Leicester } & \text { University of Nottingham } & \\ \text { Mary Hamilton } & \text { University of Lancaster } & \text { Corresponding Editor } \\ \text { Maria Slowey } & \text { University of Glasgow } & \\ \text { Richard Taylor } & \text { University of Leeds } & \\ \text { Mary Thorpe } & \text { Open University } & \\ \text { Miriam Zukas } & \text { University of Leeds }\end{array}$

Manuscripts for publication may be submitted to any member of the Editorial Board, or directly to the Editor, Dr Richard Edwards, Institute of Education, University of Stirling, Stirling, FK9 4LA, UK, e-mail r.g.edwards@stir.ac.uk.

Books for review should be sent to the Reviews Editor, Dr Janet Bunker, 19 Scotsdowne Road, Trumpington, Cambridge CB2 2HU, UK.

\section{Subscription information}

UK: Individuals $£ 20.00$ Institutions $£ 30.00$

Overseas: Individuals $£ 22$ (surface mail) $£ 25$ (airmail)

Institutions £33 (surface mail) £38 (airmail)

All subscription enquiries should be addressed to

The Subscriptions Department, National Institute of Adult Continuing Education,

21 De Montfort Street, Leicester LE1 7GE, UK

Telephone $++(0) 1162044200 \mathrm{Fax}++(0) 1162854514$

NIACE website: http://www.niace.org.uk

ISSN 02660830

(C) NIACE 2001

All rights reserved. No part of this publication may be reproduced, stored in a retrieval system, or transmitted in any form or by any means electronic, mechanical, phorocopying, recording or ocherwise without prior permission, in writing, of the National Institute of Adult Continuing Education (England and Wales), 21 De Monfort Street, Leicester LE1 7GE, UK.

NLACE is a registered charity, number 1002775 


\section{Notes for contributors}

1. Studies in the Education of Adults

- acknowledges and promotes the study of the education of adults as a field of study in its own right (as opposed to an academic site for other established subject areas)

- recognises the importance of theory in academic debate and encourages its development

- supports innovative work which directly challenges conventional wisdom in terms of either content or presentation

- seeks to ensure a diversity of voices and paradigms to express the variety in the field as a whole

- provides a forum for critical debate

2. Studies selects papers for publication that

- provide a clear theoretical rationale for the work discussed

- concentrace on analysis, as opposed to purely descriptive accounts

- contextualise the work so that it is understandable by an international readership

- use an accessible style of writing, concentrating on clarity and avoiding unexplained jargon

- recognise the professional and academic experience of the journal's readership

3. The Board welcomes ideas for contributions, which can take the form of:

articles: between 5,000 and 8,000 words in length

reports of research in progress: between 2,000 and 3,000 words

critical comments: on articles already published between 500 and 1,000 words

reviews of recent publications: $500-1,000$ words

Intending contributors are strongly advised to contact the Editor before submitting a full text.

4. Papers submitted are acknowledged and then read by a member of the Editorial Board, and by external referees. Authors are normally informed of the Board's decision within eight weeks of acknowledgment, with editorial comments.

5. Submissions for publication must be clearly presented on A4 (or equivalent) paper in double spacing with ample margins. Two copies of each submission, accompanied by an IBMcompatible $3^{1 / 2 "}$ disk, should be sent directly to the Editor. Articles should have a cover sheet showing the complete title, the name, professional position and full address of the author. The layout of quotations and notes must follow the conventions shown in the current number of the journal. Bibliographical references in the text should quote the author's name and date of publication thus: (Randle, 1993). They should be listed alphabetically by author at the end of the article. A detailed style sheet is available from the Editor. Where possible, an electronic version of the article should be emailed to the Editor (address on inside of front cover).

6. The Board of Studies is keen to encourage contributions from people entering into research and scholarship in the education of adults. However, the experience of refereeing suggests that before submitring, authors should ask themselves a number of key questions:

a. How does my paper relate to the aims and criteria for the journal outlined in 1 . and 2 . above?

b. Is the focus of the paper concerned with the education of adults?

c. Have I drawn sufficiently on existing literature in the field?

d. Am I providing evidence for the argument being put forward, and how robust is that evidence?

e. Is the argument coherent and focused?

f. Are the claims I am making justifiable?

g. Where appropriate, have I explained the methodology sufficiently?

h. Is it contextualised for an international audience?

i. Is it in the right format with full references and an abstract?

We are concerned that some articles are submitted at too early a stage of development and that rejection can cause disappointment to authors. These self-evaluation questions are aimed to avoid that and support authors in preparing submissions to this journal. 